\title{
Phytochemical Evaluation and Chromatographic Fingerprint Analysis on Flavonoids Compounds in Leucas aspera (Willd.) Link Leaf by HPTLC
}

\author{
Vellaichamy Muthupandi Annapandian ${ }^{1,2 *}$, Rajagopal Shanmuga Sundaram¹, Swaminathan Gomathi ${ }^{3}$
}

\section{Vellaichamy Muthupandi Annapandian ${ }^{1,2 *}$, Rajago- pal Shanmuga Sundaram ${ }^{1}$, Swaminathan Gomathi ${ }^{3}$ 'Department of Pharmacology, JKK Nat- traja College of Pharmacy, Komarapa- layam, Namakkal, Tamil Nadu, INDIA. ${ }^{2}$ Academic Research Department, Narayana Hrudayalaya Foundations, Bangalore, Karnataka, INDIA. ${ }^{3}$ Department of Pharmaceutical Chem- istry, JKK Nattraja College of Pharmacy, Komarapalayam, Namakkal, Tamil Nadu, INDIA.}

\section{Correspondence}

Vellaichamy M. Annapandian, M.Pharm., PGDCP., Ph.D., Consultant - Academic, Narayana Hrudayalaya Foundations, 258A, Bommasandra Industrial Area, Bangalore - 560099,

Karnataka, INDIA.

Phone: +91-9945211900

E-mail: vmannapandian@gmail.com

History

- Submission Date: 09-07-2017;

- Review completed: 18-07-2017;

- Accepted Date: 27-08-2017

DOI : 10.5530/pj.2017.6.147

Article Available online

http://www.phcogj.com/v9/i6

Copyright

(C) 2017 Phcog.Net. This is an openaccess article distributed under the terms of the Creative Commons Attribution 4.0 International license.

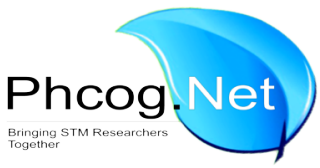

\begin{abstract}
Introduction: Leucas aspera is one of the important medicinal plants in Indian medical system and it belongs to Lamiaceae family. Leucas aspera (Willd) Link (L. aspera) belongs to Leucas genus, widely distributed throughout India. L. aspera has many vernacular names and is commonly known as Thumbai. Flavonoid is a phenolic compound which is widely distributed in the plants and responsible for many biological activities. Preliminary phytochemical analysis gives a broad idea to the researchers for their further research. Methods: In this present study, we did a preliminary phytochemical screening, quantitative estimation of total flavonoids and fingerprinting profile of flavonoids compounds using five different solvent extracts obtained from leaves of $L$. aspera. Results: Preliminary phytochemical screening confirmed the presence of flavonoid compounds in L. aspera. Higher concentration of total flavonoid compounds was noted in ethanol extract compared to petroleum ether, chloroform, isopropyl alcohol and ethyl acetate extracts. A densitometric high performance thin layer chromatography (HPTLC) study showed more number of flavonoid compounds are present in ethanol extract compared to other solvents. Conclusions: Results of this study revealed, L. aspera leaf is a rich source of flavonoid content and it can be used to alleviate many chronic illness and various diseases. This study results warrants for further isolation, identification and characterization of active principle which is responsible for the biological activity.
\end{abstract}

Key words: Chromatographic, Flavonoids, Fingerprinting, HPTLC, Leucas aspera.

\section{INTRODUCTION}

Leucas aspera (Willd) Link (L. aspera) belongs to Lamiaceae (Labiatae) family. It is a common weed in India and widely distributed throughout the country. The leaves of $L$. aspera are obtuse, linear or linearly lanceolate or petiolate. The length of the leaf is about $8.0 \mathrm{~cm}$ and $1.25 \mathrm{~cm}$ in broad. Though L. aspera has many vernacular names depending on the region, most commonly known as Thumbai. ${ }^{1}$ The juice of L. aspera leaves are used as remedy for chronic skin eruptions, chronic rheumatism and psoriasis. $^{2}$ In villages $L$. aspera leaves are used as insecticides and mosquito repellent. Flavonoids are the phenolic compounds that comprise in large group of plants and widely distributed throughout the plant kingdom. Several studies have suggested that flavonoids are effective in prevention and treatment of many diseases. ${ }^{3,4}$ In our present study, we attempted to evaluate the presence of flavonoids content and fingerprinting profile of flavonoids present in the $L$. aspera leaves by HPTLC technique using different solvent extracts.

\section{MATERIALS AND METHODS}

Plant materials

The plant $L$. aspera was collected from southern part of Tamil Nadu (Kandappakottai, Dindigul District) and was authenticated by Prof. P Jayaraman, Director, Institute of Herbal Botany and Anatomy Research Centre, Tambaram, Chennai (PARC/2014/ 2272). The leaves were then isolated, cleaned and dried under sun shadow. Dried leaves were crushed to powder and passed through pharmaceutical sieve no 40 and 80 . Any materials which retained at sieve- 80 were collected and used for extraction.

\section{Preparation of crude extracts}

Five different solvents were used for extraction process with increase in polarity, which included petroleum ether $\left(60-80^{\circ} \mathrm{C}\right)$, ethyl acetate, chloroform, ethanol (70\%) and isopropyl alcohol. Soxhlet apparatus was used for petroleum ether extraction. Six hundred $g$ of powdered leaf was extracted with $2.5 \mathrm{~L}$ of petroleum ether $\left(60-80^{\circ} \mathrm{C}\right)$. Excess solvent was removed by distillation method. Crude extract

Cite this article: Annapandian VM, Sundaram RS, Gomathi S. Phytochemical Evaluation and Chromatographic Fingerprint Analysis on Flavonoids Compounds in Leucas aspera (Willd.) Link Leaf by HPTLC. Pharmacog J. 2017;9(6):942-6. 
was dried at vacuum desiccators and stored in a glass bottle at $-20^{\circ} \mathrm{C}$ for further studies. All other solvent extracts were prepared by cold maceration technique. Weighed powder were soaked in individual solvents viz., ethyl acetate $(200 \mathrm{~g}+1.0 \mathrm{~L})$, chloroform $(200 \mathrm{~g}+1.0 \mathrm{~L})$, isopropyl alcohol $(200 \mathrm{~g}+1.0 \mathrm{~L})$ and ethanol $70 \%(600 \mathrm{~g}+2.5 \mathrm{~L})$ in a separate round bottom flask for $72 \mathrm{~h}$ with occasional shaking. After soaking, the mixture was heated at $30 \pm 5^{\circ} \mathrm{C}$ for $60 \mathrm{~min}$. Heated solution was cooled to room temperature and filtered through muslin cloth and Whatman filter paper. Excess solvents were then removed by distillation method and allowed to evaporate at room temperature. Dried crude extracts were collected and stored in an individual glass bottles at $-20^{\circ} \mathrm{C}$ for further studies.

\section{Qualitative phytochemical screening of flavonoids}

All the five solvent extracts were screened for the presence of flavonoids with all respective testing procedures include shinoda's test, alkaline reagent test, lead acetate test and sulphuric acid test as described in the textbook by Harborne JB (eds). ${ }^{5}$

\section{Quantitative estimation of total flavonoid compounds}

Total flavonoids were estimated by using spectrophotometric technique. ${ }^{6}$ Flavonoids give yellow color when treated with aluminum chloride reagent $(1 \% \mathrm{w} / \mathrm{v})$ and this principle was used in flavonoid estimation. Rutin was used as standard in methanol solution $(100 \mathrm{mg} / \mathrm{ml})$. Test sample was prepared with methanol to the final concentration of $100 \mathrm{mg} / \mathrm{ml}$. One $\mathrm{ml}$ of test and standard solutions were taken in a separate $10 \mathrm{ml}$ volumetric flask and $1.0 \mathrm{ml}$ of aluminum chloride reagent was added to both test and standard solutions. Volumes were made up to $10 \mathrm{ml}$ with methanol and optical density measured at $410 \mathrm{~nm}$ against blank solution exactly at $15 \mathrm{~min}$ after adding aluminum chloride reagent.

$$
\begin{aligned}
& (\mathrm{T}-\mathrm{TB}) \times \text { Wt. of } \mathrm{Std} \times 5 \times \\
& \text { Total flavonoids }=\frac{\text { Vol of Std } \times \text { Total vol of Std }}{(S-S B) \times 100 \times 100 \times} \times \% \text { purity of Std } \\
& \text { Vol of Sample } \times \text { Wt of Sample }
\end{aligned}
$$

T -- sample (test) solution; $\mathrm{S}$-- standard solution; TB -- sample blank; SB -- standard blank; T - TB -- absorbance of test; S - SB -- absorbance of standard
* Subtract the corresponding blank values from the standard and test absorbance values $(\mathrm{S}-\mathrm{SB} ; \mathrm{T}-\mathrm{TB})$. Calculate the flavonoid content with respect to Rutin and express as \% w/w of flavonoids.

\section{Thin layer chromatography (TLC) Studies}

Thin Layer Chromatography has been used for isolation of compounds form the crude extracts. Pre-coated silica gel on aluminum plates (Merck pre-coated Al. Sheets - 1.05554) were used as adsorbent for elution. Crude extracts were dissolved in HPLC-grade methanol to the final concentration of $10 \mathrm{mg} / \mathrm{mL}$. Based on trial and error method toluene: ethyl acetate: acetic acid (55: 45: 1) was used as mobile phase (eluting agent). Spots were observed at $254 \mathrm{~nm}$ and $366 \mathrm{~nm}$.

\section{HPTLC finger printing profile of flavonoids}

For fingerprinting studies, a densitometric high performance thin layer chromatographic (HPTLC) system was used. The HPTLC system equipped with Shimadzu flying spot densitometer CS9301, Camag TLC Scanner-3 with win Cats Planar chromatography manager, Applicator CAMAG - Linomat IV and Linomat V and saturated developing chamber CAMAG Twin trough 20x20 cm was used. HPLC grade Methanol was used as a solvent for all the extracts solution $(10 \mathrm{mg} / \mathrm{mL})$. Spots were made on a pre-coated plate \{Silica gel 60 F254: (Merck pre-coated Al. Sheets - 1.05554)\} with an aid of sampling machine, and solvent front run up to $9 \mathrm{~cm}$ height. Ethyl acetate: acetic acid: formic acid: water (100:11:11:10) was used as a mobile phase and 1\% aluminum chloride solution was used as spraying agent for flavonoids profiling. Rutin was used as a standard reference.

\section{RESULTS}

\section{Phytochemical studies}

The present study was carried out on the crude extracts of petroleum ether, ethyl acetate, chloroform, ethanol and isopropyl alcohol obtained from leaves of L. aspera. Petroleum ether, isopropyl alcohol and ethanol extracts had shown to strong positive for flavonoids test than chloroform and ethyl acetate extracts Table 1. Quantitative estimation showed the higher concentration of flavonoids present in the ethanol extract compared

\begin{tabular}{|c|c|c|c|c|c|}
\hline Test for flavonoids & $\begin{array}{l}\text { Petroleum } \\
\text { ether extract }\end{array}$ & $\begin{array}{l}\text { Ethyl Acetate } \\
\text { extract }\end{array}$ & $\begin{array}{l}\text { Chloroform } \\
\text { extract }\end{array}$ & $\begin{array}{c}\text { Isopropyl } \\
\text { alcohol extract }\end{array}$ & $\begin{array}{l}\text { Ethanol } \\
\text { extract }\end{array}$ \\
\hline Shinoda's Test & ++ & + & + & ++ & ++ \\
\hline Alkaline reagent test & ++ & + & + & + & ++ \\
\hline Lead acetate test & + & + & + & ++ & ++ \\
\hline Sulphuric acid test & ++ & + & + & + & + \\
\hline
\end{tabular}
to other solvent extracts. The summary of amount of total flavonoids content present in each extract was described in Table 2.

+ Positive. ++ Strong positive.

Table 2: Summary of total flavonoids compounds present in L. aspera leaf extracts.

\begin{tabular}{cc}
\hline Leucas aspera leaf extracts & Total flavonoids content $(\mathbf{g})$ \\
\hline Petroleum ether extract & 13.22 \\
Ethyl Acetate extract & 14.90 \\
Chloroform extract & 13.22 \\
Isopropyl alcohol extract & 13.39 \\
Ethanol extract & 15.97 \\
\hline
\end{tabular}

* all values are expressed in g per $100 \mathrm{~g}$ of extract. 
Table 3: Peak table with RF values, height and area of flavonoids and unknown compounds present in $L$. aspera leaf extracts.

\begin{tabular}{lccccc}
\hline Track & Peak & Rf & Height & Area & Assigned substance \\
\hline Rutin & 1 & 0.67 & 609.5 & 21679.7 & Rutin \\
Rutin & 2 & 0.77 & 31.1 & 598.4 & Unknown \\
PELA & 1 & 0.66 & 17.1 & 329.1 & Flavonoid \\
PELA & 2 & - & - & - & Unknown \\
EALA & 1 & - & - & - & Unknown \\
CFLA & 1 & - & - & - & Unknown \\
IALA & 1 & - & - & - & Unknown \\
IALA & 2 & 0.70 & 33.0 & 983.9 & Flavonoid 1 \\
IALA & 3 & 0.76 & 36.7 & 871.6 & Flavonoid 2 \\
EELA & 1 & 0.61 & 46.2 & 1575.8 & Flavonoid 1 \\
EELA & 2 & 0.66 & 63.7 & 1802.6 & Flavonoid 2 \\
EELA & 3 & 0.67 & 165.7 & 5368 & Flavonoid 3
\end{tabular}

Table 4: HPTLC fingerprint profile of flavonoids present in different solvent extracts of $L$. aspera leaf.

\begin{tabular}{ccccccc}
\hline Rf value & Rutin & Petroleum ether & Ethyl acetate & Chloroform & Isopropyl alcohol & Ethanol \\
\hline 0.61 & - & - & - & - & - & - \\
0.65 & - & - & + & - & - & + \\
0.66 & - & + & - & - & - & + \\
0.67 & + & - & - & - & - & - \\
0.70 & - & - & - & - & + & - \\
0.74 & - & - & - & - & - \\
0.76 & + & + & - & - \\
0.77 & & & - & - & - & + \\
\hline
\end{tabular}

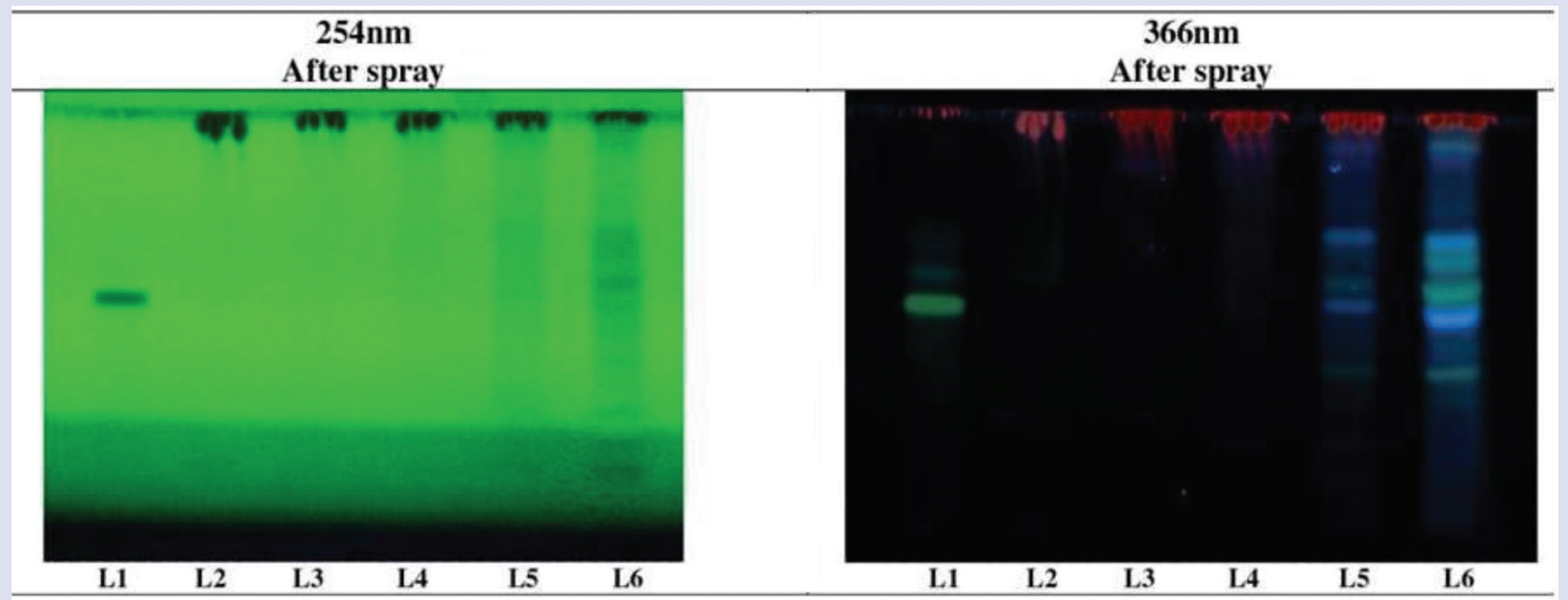

L1- Rutin standard; L2-Petroleum ether; L3-Chloroform; L4-Ethyl acetate; L5-Isopropyl alcohol; L6-Ethanol

Figure 1: HPTLC profile of L. aspera leaves under UV 254 and $366 \mathrm{~nm}$. 


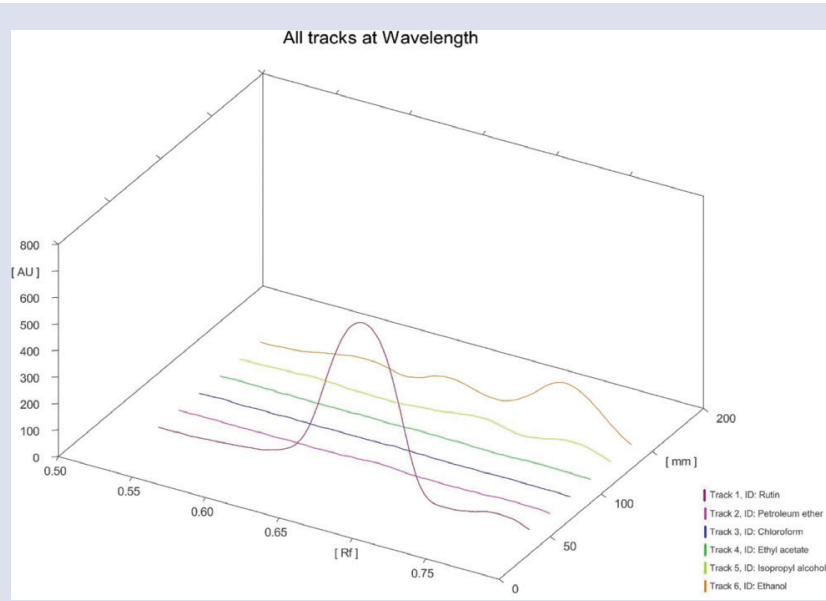

Figure 2: HPTLC chromatogram of L. aspera leaf extracts: All tracks at wavelengths.

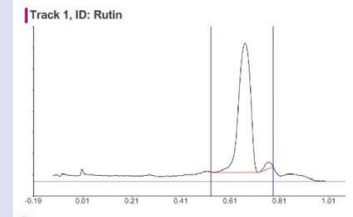

| Track 2. 10: Petroleum ether

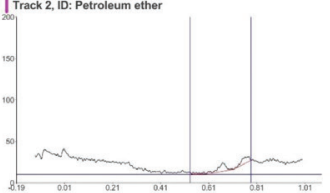

ITrack 3, ID: Chloroform

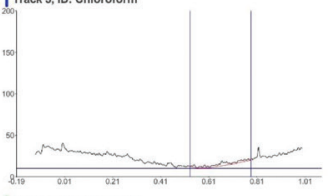

| Track 4, ID: Ethyl acetato

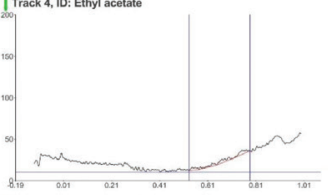

I Track 5, ID: lsopropyl alcohol

$\underset{\substack{\mid \\ 300 \\ 250}}{\text { Track }}$

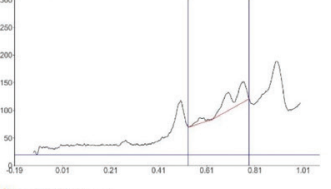

| Track 6, 10: Ethanol

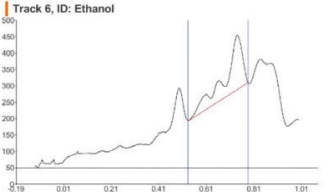

15

Figure 3: HPTLC chromatogram of different solvent extracts of $L$. aspera leaf.

\section{Chromatographic studies}

HPTLC studies showed blue, greenish blue and yellowish green coloured fluorescent zones at UV $366 \mathrm{~nm}$ after derivatization. These fluorescent zones confirmed the presence of flavonoids in the L. aspera leaf extracts Figure 1. The order of presence of flavonoids (fluorescent zone) in L. aspera extract was ethanol $>$ isopropyl alcohol $>$ ethyl acetate $>$ chloroform $>$ petroleum ether. The Rf value of the extracts were found to be $0.61,0.66,0.67,0.70,0.76$ and 0.77 of the peaks. Out of 10 peaks 6 were identified as flavonoid compounds. The complete details of $\mathrm{Rf}$ values and area of the peaks were presented in Table 3. Rutin was used as the standard compound for flavonoid identification.

\section{DISCUSSION}

Preliminary phytochemical studies give a broad idea to researchers for their further research. In this present study, preliminary phytochemical screening confirmed the presence of flavonoids in the $L$. aspera leaf extracts. Out of which, petroleum ether (non-polar), isopropyl alcohol (polar) and ethanol (polar) extracts had shown strong positivity. The quantitative estimation revealed, total flavonoid compounds are almost equally present in the L. aspera leaf extracts. But the HPTLC fingerprint profiles showed, among the five solvent extracts, flavonoids were predominantly found in ethanol extract of $L$. aspera followed by isopropyl alcohol, ethyl acetate, chloroform and petroleum ether extracts. At least two types of flavonoids were observed in each extract Figure 2 and 3. Four unknown compounds were observed by HPTLC fingerprint profile of flavonoids in different solvent extracts of $L$. aspera leaves. The summary of HPTLC chromatogram of different solvent extracts of $L$. aspera is presented in Table 4. Our study findings are comparable with the existing literature where they used methanol extract of whole plant of L. aspera. ${ }^{7}$ Flavonoids have potent antioxidant properties and it can modulate the various enzymatic activities due to their interaction with various biomolecules. ${ }^{8}$ Traditionally $L$. aspera was used as insecticide and antipyretic. Several studies showed L. aspera has a potential anti-diabetic effect ${ }^{9-11}$, larvicidal effect ${ }^{12-14}$ and antimicrobial effect. ${ }^{15-17}$

\section{CONCLUSION}

In recent years the usage of Indian Medicine system and Traditional Medicine systems are increased. Many people have started using alternative medicines particularly in chronic disorders. Herbals and phytocompounds based medicines are believed to be less toxic and effective. Leucas aspera is a good source for flavonoid compounds and seems to have promising phytocompounds that can be used to alleviate many chronic illnesses with its isolated active compounds. Further studies are required for identification and characterization of flavonoid compounds present in the Leucas aspera leaves, which is potential for therapeutic applications.

\section{ACKNOWLEDGEMENT}

None

\section{FINANCIAL SUPPORT AND SPONSORSHIP}

Nil

\section{CONFLICTS OF INTEREST}

All authors have no conflict of interest. 


\section{ABBREVIATIONS USED}

CFLA: Chloroform extract of Leucas aspera; EALA: Ethyl acetate extract of Leucas aspera; EELA: Ethanol extract of Leucas aspera; g: gram; HPLC: High performance liquid chromatography; HPTLC: High performance thin layer chromatography; IALA: Isopropyl alcohol extract of Leucas aspera; L: Litre; L. aspera: Leucas aspera (Willd) Link; PELA: Petroleum ether extract of Leucas aspera; TLC: Thin layer chromatography.

\section{REFERENCES}

1. Rai V, Agarwal M, Agnihotri A, Khatoon S, Rawat A, Mehrotra S. Pharmacognostical Evaluation of Leucas aspera Link. Nat Prod Sci. 2005;11(2):109-14.

2. Kirtikar KR. Indian Medicinal Plants: Vol. III. (2) Sec ed., Lalit Mohan Basu, Allahabad, India. 1593

3. Middleton E, Kandaswami C, Theoharides TC. The effects of plant flavonoids on mammalian cells: implications for inflammation, heart disease, and cancer. Pharmacological Rev.2000;52(4):673-751

4. Ren W, Qiao Z, Wang H, Zhu L, Zhang L. Flavonoids: promising anticancer agents. Med Res Rev. 2003;23(4):519-34.

5. Harborne J. Phytochemical Methods: A Guide to Modern Techniques of Plant Analysis. Third ed., Springer Science and Business Media. London. 1998. pp.334.

6. Chang $\mathrm{C}-\mathrm{C}$, Yang $\mathrm{M}-\mathrm{H}$, Wen $\mathrm{H}-\mathrm{M}$, Chern J-C. Estimation of total flavonoid content in propolis by two complementary colorimetric methods. J Food Drug Anal. 2002;10(3):178-82.

7. Karthikeyan S, Sivakumar A, Anbalagan M, Nalini E, Gothandam KM. Finger Printing of Alkaloids, Steroids and Flavonoids using HPTLC of Leucas aspera L.Whole Plant ethanolic Extract. J. Pharm. Sci. and Res. 2013;5:67-71.

8. Catopano AL: Antioxidant effect of flavonoids. Angiology. 1997;48(1):39-46.(44)

9. Mannan A, Das H, Rahman M, Jesmin J, Siddika A, Rahman M, et al. Antihyperglycemic activity evaluation of Leucas aspera (Willd.) Link leaf and stem and Lannea coromandelica (Houtt.) Merr. bark extract in mice. Adv Nat Applied Sci.
2010;4(3):385-8.

10. Gupta N, Agarwal M, Bhatia V, Sharma RK, Narang E. A comparative anti-diabetic and hypoglycaemic activity of the crude alcoholic extracts of the plant Leucas aspera and seeds of Pithecellobium bigeminum in rats. IJRAP. 2011;2:275-80.

11. Tukaram T, Parvati CV, Venkata-Rao N, Patil P, Srinivas-Rao N. Evaluation of the extracts of Leucas aspera on biochemical profiles in experimental model of diabetes mellitus (Type- I) in rats. Inter Res J Pharm. 2011;2(3):246-8.

12. Suganya G, Karthi S, Shivakumar MS. Larvicidal potential of silver nanoparticles synthesized from Leucas aspera leaf extracts against dengue vector Aedes aegypti. Parasitol Res. 2014;113(3):875-80

13. Elumalai D, Hemavathi M, Hemalatha P, Deepaa CV, Kaleena PK. Larvicidal activity of catechin isolated from Leucas aspera against Aedes aegypti, Anopheles stephensi, and Culex quinquefasciatus (Diptera: Culicidae). Parasitol Res. 2016;115(3):1203-12

14. Kovendan K, Murugan K, Vincent S, Barnard DR. Studies on larvicidal and pupicidal activity of Leucas aspera Willd. (Lamiaceae) and bacterial insecticide Bacillus sphaericus, against malarial vector, Anopheles stephensi Liston. (Diptera: Culicidae). Parasitol Res. 2012;110(1):195-203.

15. Rahman MA, Islam MS. Antioxidant, antibacterial and cytotoxic effects of the phytochemicals of whole Leucas aspera extract. Asian Pac J Trop Biomed. 2013;3(4):273-9

16. Chew AL, Jessica JJA, Sasidharan S. Antioxidant and antibacterial activity of different parts of Leucas aspera. Asian Pac J Trop Biomed. 2012;2(3):176-80.

17. Mangathayaru K, Lakshmikant J, Shyam Sundar N, Swapna R, Grace XF, Vasantha J. Antimicrobial activity of Leucas aspera flowers. Fitoterapia. $2005 ; 76(7): 752-4$
GRAPHICAL ABSTRACT

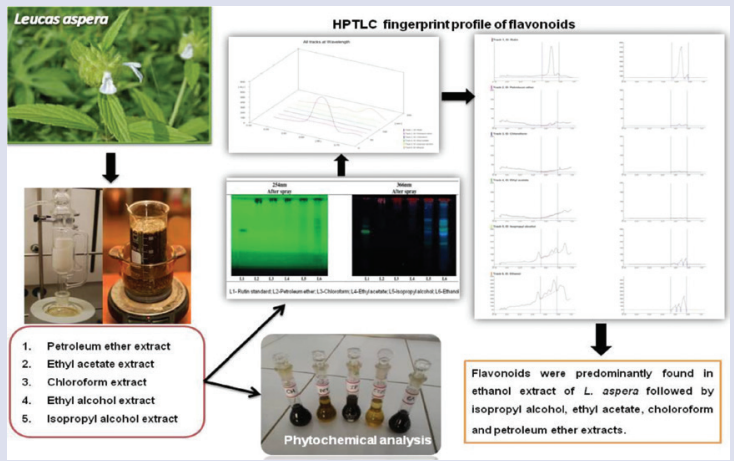

ABOUT AUTHORS

\section{SUMMARY}

- Leucas aspera is a good source for flavonoid compounds.

- Petroleum ether (non-polar), isopropyl alcohol (polar) and ethanol (polar) extracts had shown strong positivity in preliminary phytochemical screening.

- Quantitative estimation revealed, total flavonoid compounds are almost equally present in the L. aspera leaf extracts.

- HPTLC fingerprint profiles showed, flavonoids were predominantly found in ethanol extract of $L$. aspera followed by isopropyl alcohol, ethyl acetate, chloroform and petroleum ether extracts.

- At least two types of flavonoids were observed in each extract.

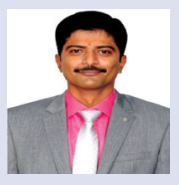

Vellaichamy M. Annapandian, is a Consultant, Academic Research, Narayana Hrudayalaya Foundations, Bangalore, India. He has published more than 10 peer review research articles, 1 book chapter and 12 conference proceedings. The author's work has been published in Medical, Pharmacology and Phytopharmacy journals.

Cite this article: Annapandian VM, Sundaram RS, Gomathi S. Phytochemical Evaluation and Chromatographic Fingerprint Analysis on Flavonoids Compounds in Leucas aspera (Willd.) Link Leaf by HPTLC. Pharmacog J. 2017;9(6):942-6. 